\title{
Effects of Helicobacter pylori eradication therapy on hyperammonaemia in patients with liver cirrhosis
}

\author{
H Miyaji, S Ito, T Azuma, Y Ito, Y Yamazaki, Y Ohtaki, F Sato, M Hirai, M Kuriyama, \\ Y Kohli
}

\begin{abstract}
Background and aims-Helicobacter pylori has strong urease activity. Ammonia produced by $H$ pylori in the stomach can be a source of systemic ammonia in patients with hepatic dysfunction. The effect of the eradication of $H$ pylori on hyperammonaemia was examined in patients with liver cirrhosis. Subjects and methods-Ammonia concentrations in blood and gastric juice were analysed in 50 patients with liver cirrhosis and hyperammonaemia. All patients were first treated with a low protein diet, kanamycin, lactulose, and branched chain enriched amino acid solution. Hyperammonaemia remained in 18 patients. These 18 patients were divided into three groups according to the status of $H$ pylori infection; those with a diffuse distribution of $H$ pylori in the stomach (group I), those with a regional distribution (group II), and those without $H$ pylori (group III). These patients were given $30 \mathrm{mg}$ iansoprazole, $1000 \mathrm{mg}$ amoxicillin, and $400 \mathrm{mg}$ clarithromycin or $500 \mathrm{mg}$ metronidazole for two weeks to eradicate $H$ pylori.
\end{abstract}

Results-In group I ammonia concentrations in blood and gastric juice were significantly reduced after $H$ pylori eradication. The blood ammonia concentration at 12 weeks after the eradication was still significantly lower than that before eradication. In groups II and III the ammonia concentrations in blood and gastric juice were not significantly reduced after eradication therapy.

Conclusions-The diffuse distribution of $H$ pylori in the stomach contributes partly to hyperammonaemia in patients with liver cirrhosis, and the eradication of $H$ pylori is effective in patients with hyperammonaemia with diffuse $H$ pylori infection in the stomach.

(Gut 1997; 40: 726-730)

Keywords: Helicobacter pylori, hyperammonaemia, liver cirrhosis, urease.

Chronic hepatic encephalopathy is a disabling complication of cirrhosis and its management is difficult. Patients have generally been treated with restriction of dietary protein intake ${ }^{1}$ and given non-absorbable disaccharides ${ }^{2-5}$ and oral antibiotics $^{6-9}$ to reduce the production and absorption of ammonia. Ammonia is of key importance in the pathogenesis of hepatic encephalopathy, ${ }^{10}{ }^{11}$ and hyperammonaemia in patients with cirrhosis is considered to be produced by bacterial urease in the gut flora. $H$ pylori, a Gram negative microaerophilic bacterium that infects the gastric mucosa of humans, is probably the most common infection worldwide. ${ }^{12-14} \mathrm{H}$ pylori infection is widely accepted as the predominant cause of chronic gastritis and is strongly associated with peptic ulcer, ${ }^{15} 16$ gastric cancer, ${ }^{17-20}$ and mucosa associated lymphoid tissue (MALT) lymphoma. ${ }^{21} H$ pylori is also known to produce copious amounts of ammonia due to its strong urease activity, many times greater than that of urease positive enterobacteria. ${ }^{22-24}$ Therefore, we hypothesised that gastric ammonia produced by $H$ pylori can affect the systemic ammonia concentration in patients with liver dysfunction. Previously, we examined the effect of the instillation of $H$ pylori in the stomach on the systemic ammonia concentration in rats with cirrhosis induced by carbon tetrachloride. That study showed that the ammonia concentrations in portal and venous blood significantly increased after the instillation of $1 \mathrm{ml} 10^{7}$ colony forming units $(\mathrm{CFU}) / \mathrm{ml} H$ pylori in the stomach of cirrhotic rats, and suggested that the ammonia produced by $H$ pylori has a role in the pathogenesis of hyperammonaemia when this organism is widely distributed and is present in large numbers in the stomach, particularly in the presence of liver cirrhosis. ${ }^{25}$ We also reported the effect of the eradication of $H$ pylori on hyperammonaemia in two patients with cirrhosis, and suggested that ammonia production by $H$ pylori in the stomach contributes to the systemic ammonia in patients with liver cirrhosis. ${ }^{26}$ However, several investigators have questioned whether the effect of the eradication therapy on hyperammonaemia is due to the eradication of $H$ pylori or to the non-specific effect of antibiotic therapy on the ammonia producing gut flora. ${ }^{27}{ }^{28}$ In the present study, we therefore examined the effect of the eradication of $H$ pylori on hyperammonaemia in patients with adequate treatment for gut flora.

\section{Methods}

We studied 50 patients with liver cirrhosis and hyperammonaemia ( 31 men and 19 women, 43-83 years old, mean age $63.3 ; 19$ were Childs-Pugh stage A, 18 were $B$, and 13 were C). All had normal renal function and had never received any anti- $H$ pylori treatment. All patients were admitted to Fukui Medical School. Diagnosis of cirrhosis was carried out 
by history, clinical examination, laboratory findings, and liver biopsy when not contraindicated. This study was performed according to the principles of the Declaration of Helsinki, and consent was obtained from each patient after full examination of the nature and protocol of the study.

All patients were given kanamycin (2000 $\mathrm{mg} /$ day) for two weeks before $H$ pylori eradication therapy to reduce the effect of the ammonia producing gut flora on hyperammonaemia. ${ }^{6-9}$ During the examination period lactulose was given to all patients and the amount was adjusted individually to induce two to four bowel movements a day. ${ }^{2-5}$ Protein intake was restricted to about $40 \mathrm{~g}$ daily and there were no changes in diet during the examination period. A branched chain enriched amino acid solution (Aminoleban ${ }^{\circledR}$, Otsuka, Tokushima, Japan) was also given intravenously to all patients to correct the plasma amino acid imbalance. ${ }^{29-31}$ The ammonia concentrations in blood were measured early in the morning after fasting. $H$ pylori infection was diagnosed by phenol red dye spraying endoscopy, culture, histology, and the presence of serum anti- $H$ pylori IgG. Subjects who had $H$ pylori identified by more than two tests were defined as $H$ pylori positive, and those not found to have $H$ pylori by any tests were defined as negative. During the endoscopy gastric juice was collected for measurement of ammonia concentration.

Phenol red dye spraying endoscopy is a good indicator for detecting the distribution of $H$ pylori in the stomach. ${ }^{1632} 33$ The procedure was as described previously. The basic principle behind this technique is the same as the biopsy urease test. Phenol red solution $(0.05 \%)$ containing urea $(0.5 \mathrm{M})$ is sprayed onto the gastric mucosa directly through the endoscope instead of in vitro using biopsy specimens. Ammonia is produced by $H$ pylori, with its strong urease activity, and the colour of the sprayed dye solution changes from yellow to red in a few minutes. The colour change is classified into three types; diffuse, regional, and unstained. We first examined the relation of the distribution pattern of the endoscopy and the ammonia concentration in gastric juice in 68 healthy volunteers (41 men and 27 women, 43-88 years old, mean age $58 \cdot 3$ ).

Twenty four of the 50 patients were $H$ pylori positive and 26 were negative. After treatment with a low protein diet, kanamycin, lactulose, and aminoleban ${ }^{\circledR}$, hyperammonaemia was still present in 18 cases ( 12 were $H$ pylori positive and six were $H$ pylori negative). These 12 patients were given $30 \mathrm{mg}$ lansoprazole, 1000 $\mathrm{mg}$ amoxicillin, and $400 \mathrm{mg}$ clarithromycin or $500 \mathrm{mg}$ metronidazole daily for two weeks for the eradication of $H$ pylori. Six $H$ pylori negative cases were also given the eradication therapy as controls. Four weeks later, after eradication therapy ended, endoscopy was performed again to study $H$ pylori eradication and also to collect gastric juice to measure the ammonia concentration. The blood ammonia concentration was also measured at 12 weeks after the eradication therapy.
Urease activity of $H$ pylori isolates derived from 24 patients was also measured as described previously. ${ }^{24} \mathrm{H}$ pylori was isolated from biopsy samples in the patients described above using a sterilised endoscope. $H$ pylori isolates obtained were cultured on TSA-II agar plates (Nippon Beckton Dickinson, Tokyo, Japan) at $37^{\circ} \mathrm{C}$ under microaerobic conditions $\left(\mathrm{O}_{2} 5 \%, \mathrm{CO}_{2} 15 \%, \mathrm{~N}_{2} 80 \%\right)$. $\mathrm{H}$ pylori isolates $\left(\sim 10^{5} \mathrm{CFU}\right)$ were cultured at $37^{\circ} \mathrm{C}$ in $20 \mathrm{ml}$ brucella broth containing $5 \%$ fetal calf serum. Broth cultures were incubated under microaerobic conditions on a gyratory shaker at 120 rpm for three days. The growth of $H$ pylori was calculated by measuring the optical density at $560 \mathrm{~nm}$ of broth culture medium between each $H$ pylori isolate and culture medium only. After a three day culture, pellets were obtained by centrifugation and used for the measurement of urease activity. $H$ pylori pellets were washed with ice cold phosphate buffered saline three times, and then resuspended in $0.5 \mathrm{ml}$ sonication buffer $(20 \mathrm{mM}$ sodium phosphate buffer, $\mathrm{pH}$ 7·4, $1 \mathrm{mM}$ 2-mercaptoethanol, 1 mM EDTA). The pellet was sonicated on ice, then centrifuged at $120000 \mathrm{rpm}$ in a Beckman TLA120.2 rotor for nine minutes. Urease activity in the supernatants obtained was measured as the ammonia production rate from urea. The reaction was carried out for 30 minutes at $37^{\circ} \mathrm{C}$ using $400 \mathrm{mM}$ urea solution in $100 \mathrm{mM}$ acetate buffer, $\mathrm{pH} 5.0$. The $\mathrm{pH}$ of the reaction mixture before and after each reaction was measured to confirm that it remained constant during the reaction. Ammonia produced in the reaction was estimated by means of the indophenol reaction. A standard curve was constructed from an ammonium sulphate solution.

\section{STATISTICAL ANALYSIS}

Values are presented as mean (SD). The significance of the differences in blood and gastric juice ammonia concentrations was determined by Student's $t$ test for paired samples and that of the urease activities of $H$ pylori isolates by Student's $t$ test for unpaired samples. Significance was assigned to values of $\mathrm{p}<0.05$.

\section{Results}

In 32 out of 50 cases ( $12 \mathrm{H}$ pylori positive; seven were Childs-Pugh $A$, three were $B$, and two were $\mathrm{C}$, and $20 \mathrm{H}$ pylori negative; 12 were Childs-Pugh A and eight were B) the ammonia concentration in blood was reduced to the normal concentration after the treatment with a low protein diet, kanamycin, lactulose, and aminoleban $^{\circledR}$. However, hyperammonaemia remained in 18 cases. These 18 cases were divided into three groups according to the status of $H$ pylori infection - the patients with diffuse distribution of $H$ pylori in the stomach by phenol red dye spraying endoscopy (group I, six cases; two were Childs-Pugh B and four were $\mathrm{C}$ ), the patients with regional distribution of $H$ pylori (group II, six cases; two were Childs-Pugh B and four were $\mathrm{C}$ ), and $H$ pylori 
Clinical characteristics of study groups (mean (SD))

\begin{tabular}{lccc}
\hline & Group I & Group II & Group III \\
\hline Age & $63 \cdot 2(7 \cdot 3)$ & $59 \cdot 8(9 \cdot 6)$ & $62 \cdot 7(9 \cdot 3)$ \\
Sex (M/F) & $3 / 3$ & $4 / 2$ & $5 / 1$ \\
AST (IU/) & $57 \cdot 0(17 \cdot 1)$ & $64 \cdot 3(26 \cdot 1)$ & $61 \cdot 1(27 \cdot 2)$ \\
ALT (IU/) & $31 \cdot 8(14 \cdot 7)$ & $33 \cdot 2(14 \cdot 7)$ & $37 \cdot 7(17 \cdot 6)$ \\
Serum bilirubin (mg/dl) & $3 \cdot 2(0 \cdot 8)$ & $3 \cdot 2(1 \cdot 2)$ & $3 \cdot 2(0 \cdot 9)$ \\
Alubumin (g/dl) & $3 \cdot 0(0 \cdot 4)$ & $2 \cdot 8(0 \cdot 5)$ & $2 \cdot 9(0 \cdot 3)$ \\
Alkaline phosphatase (IU/l) & $290(112)$ & $291(83)$ & $286(101)$ \\
Cholinesterase (IU/) & $1 \cdot 6(0 \cdot 9)$ & $1 \cdot 6(1 \cdot 0)$ & $1 \cdot 9(0 \cdot 9)$ \\
Plate $\left(\times 10^{3 / \mu l}\right)$ & $6 \cdot 9(1 \cdot 9)$ & $6 \cdot 9(2 \cdot 4)$ & $7 \cdot 0(2 \cdot 1)$ \\
\hline
\end{tabular}

AST=Aspartate aminotransferase ALT=alanine aminotransferase

negative patients (group III, six cases; three were Childs-Pugh B and three were C). The Table shows the clinical characteristics of these groups. Figure 1 shows the pattern of the distribution of $H$ pylori in the stomach classified by phenol red dye spraying endoscopy. All $H$ pylori positive patients were successfully treated.
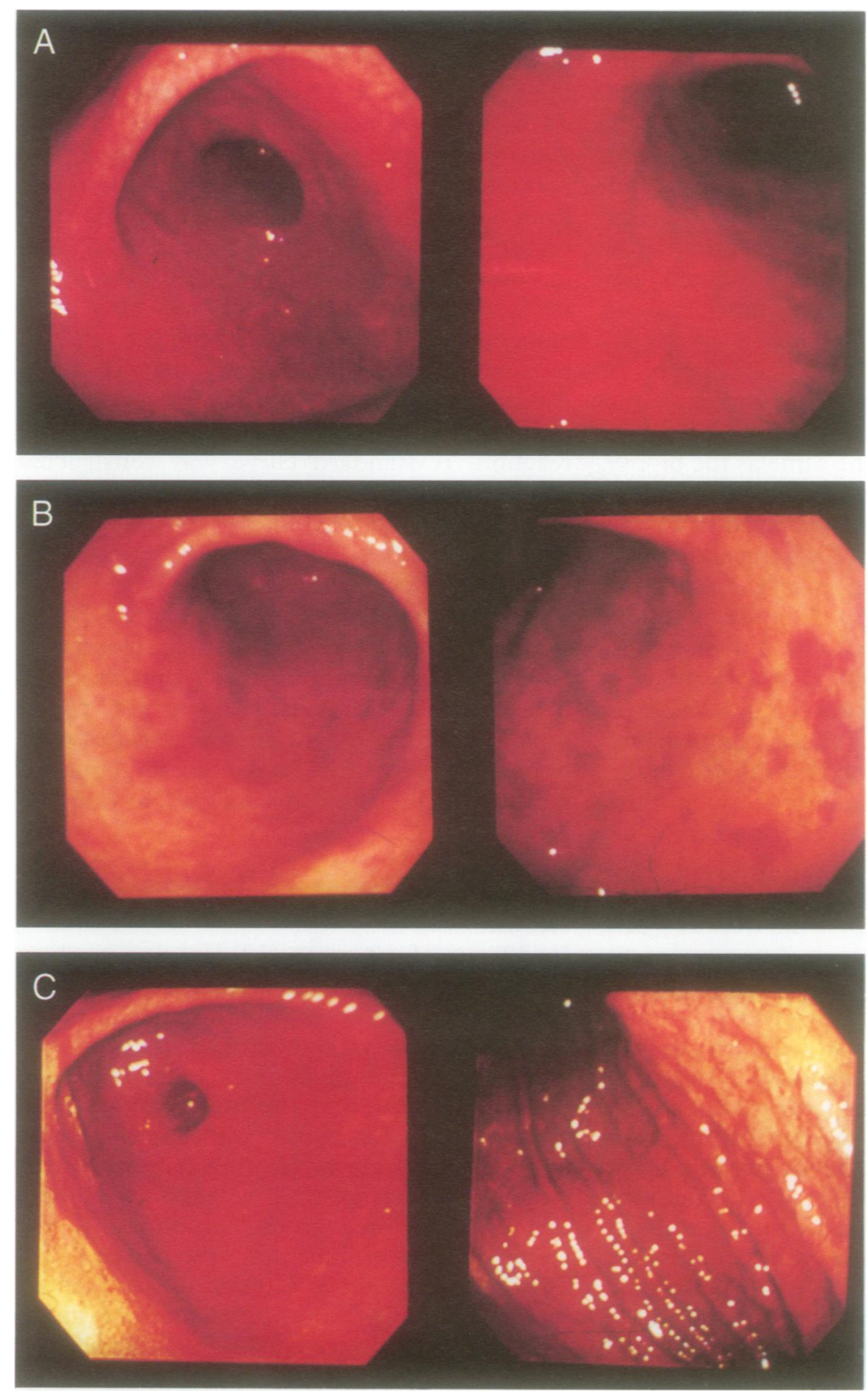

Figure 1: Pattern of the distribution of $\mathrm{H}$ pylori in the stomach was classified by the phenol red dye spraying endoscopy into $(A)$ diffuse, $(B)$ regional, and $(C)$ unstained type.
In group I, the blood ammonia concentration was $120.0(40.5) \mu \mathrm{mol} / \mathrm{l}$ before the conventional treatment to reduce the gut flora (period 1), 94.4 (31.5) $\mu \mathrm{mol} / 1$ after the conventional treatment (period 2), 57.8 (25.2) $\mu \mathrm{mol} / \mathrm{l}$ after the $H$ pylori eradication treatment (period 3), and $56.5(22 \cdot 8) \mu \mathrm{mol} / \mathrm{l}$ at 12 weeks after the eradication treatment (period 4 ). In group II, the blood ammonia concentrations were $89 \cdot 3(13 \cdot 8), 62 \cdot 4(7 \cdot 8), 56 \cdot 7(16 \cdot 1)$, and $64.5(11.9) \mu \mathrm{mol} / 1$ in periods $1,2,3$, and 4 . In group III, the blood ammonia concentrations were $90 \cdot 8(24 \cdot 2), 63.2(13.9), 61.5$ $(14.7)$, and $70.0(17.9) \mu \mathrm{mol} / \mathrm{l}$ in periods 1,2 , 3 , and 4 , respectively. In group I, the blood ammonia concentration was significantly reduced after $H$ pylori eradication compared with the concentration after conventional treatment to reduce the gut flora $(p=0 \cdot 049)$. The ammonia concentration at 12 weeks after the eradication treatment was still significantly lower than that before therapy $(p=0.038)$. In groups II and III, the ammonia concentration after conventional treatment to reduce the gut flora was significantly lower than that before treatment $(p=0.002$ and $p=0.036$, respectively), but the ammonia concentration was not significantly reduced after the eradication of $H$ pylori (Fig 2).

In the healthy volunteers, the ammonia concentration in gastric juice was significantly higher in the diffuse straining pattern $(8015$ (2182) $\mu \mathrm{mol} / \mathrm{l}$ ) than in the regional (3927 (2154) $\mu \mathrm{mol} / \mathrm{l})$ or unstained pattern (1874 (1123) $\mu \mathrm{mol} / \mathrm{l})$ (Fig 3). In patients with liver cirrhosis the ammonia concentration in gastric juice was also significantly higher in the patients with diffuse staining (group I) than in the patients with the regional (group II) or unstained (group III) patterns before the eradication treatment. The ammonia concentration in gastric juice was significantly reduced after the eradication of $H$ pylori in group I (from 8882 (2809) to 1724 (1152) $\mu \mathrm{mol} / \mathrm{l}, \mathrm{p}=0.001$ ). However, there was no significant decrease in the ammonia concentration in gastric juice after the eradication of $H$ pylori in groups II (3059 (2118) to $1953(646) \mu \mathrm{mol} / \mathrm{l}, \mathrm{p}=0 \cdot 120)$ and III (1628 (401) to 1505 (398) $\mu \mathrm{mol} / 1$, $\mathrm{p}=0 \cdot 608$; Fig 4$)$.

Figure 5 shows the urease activity of $H$ pylori isolates. There was no significant difference in urease activity of $H$ pylori isolates between groups I (16.7 (3.9) $\mathrm{mIU} / \mu \mathrm{g}$ protein) and II $(15 \cdot 0(5 \cdot 3) \mathrm{mIU} / \mu \mathrm{g}$ protein) (Fig 5$)$.

\section{Discussion}

$H$ pylori infection is a common chronic bacterial infection in humans and is considered to be one of the most important factors in the pathogenesis of peptic ulcer disease in the absence of other precipitating factors. $H$ pylori is found in around $70 \%$ of patients with gastric ulcer and $95 \%-100 \%$ of patients with duodenal ulcer. ${ }^{13-15}$ Cure of the infection heals duodenal and gastric ulcers refractory to antisecretory drugs, speeds up ulcer healing, heals ulcers without concomitant gastric acid suppression, and virtually prevents ulcer 

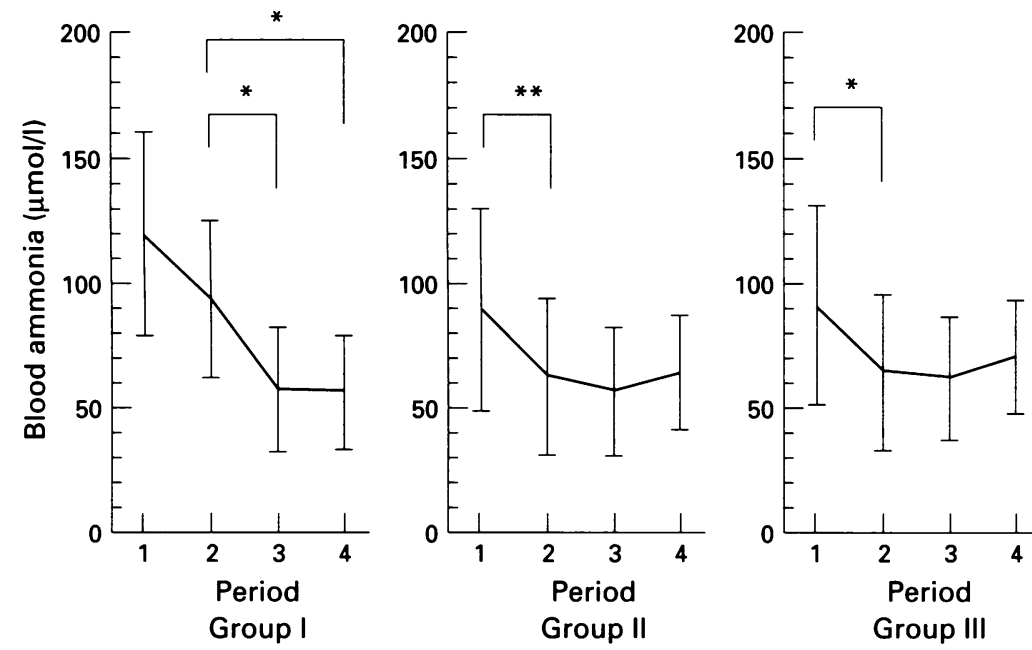

Figure 2: Changes in blood ammonia concentration in period 1 (before the conventional therapy to reduce the gut flora), period 2 (after conventional therapy), period 3 (after eradication therapy for $\mathrm{H}$ pylori), and period 4 (12 weeks after eradication therapy). Each point and bar represents the mean (SD) of the cases (group I $n=6$; group II $n=6 ;$ and group III $n=6) .{ }^{\star} p<0.05 ;{ }^{\star}{ }^{\star} p<0.01$.

recurrence. On the basis of the intervention trials, the eradication therapy is now strongly recommended for all patients with peptic ulcer infected with $H$ pylori. ${ }^{34-37}$ Forty eight per cent of the patients with liver cirrhosis in this study had $H$ pylori infection. In patients with liver cirrhosis the control of blood ammonia concentration is important to prevent hepatic encephalopathy. Ammonia produced by $H$ pylori urease in the stomach can be a source of systemic ammonia in patients with liver cirrhosis. Previously we reported the effect of the eradication of $H$ pylori on hyperammonaemia in two patients with hepatic encephalopathy. ${ }^{26}$ Quero et al also reported a fall in blood ammonia with the eradication of $H$ pylori, but they described the rise of blood ammonia two months after treatment to baseline values in patients after the eradication of $H$ pylori and suggested that the effect of the eradication of $H$ pylori on hyperammonaemia is a non-specific effect of antibiotics rather than an effect of the eradication of the organism. ${ }^{27}$ Plevris et al found no significant effect of the

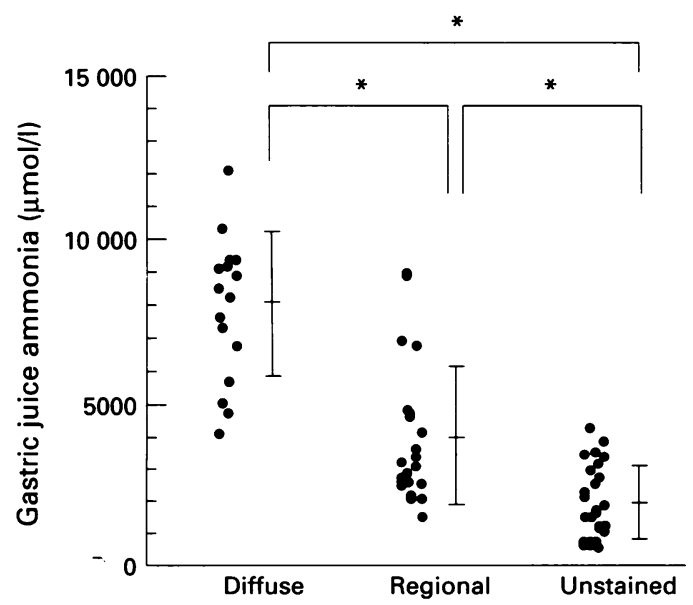

Figure 3: Ammonia concentrations in gastric juice in healthy volunteers according to the distribution pattern of $\mathrm{H}$ pylori in the stomach; each point and bar represents the mean (SD) of the cases (diffuse straining pattern $n=18$; regional straining pattern $n=22$; unstained pattern $n=28$ ). ${ }_{p}<0.001$. presence of $H$ pylori on blood ammonia up to two hours after administration of oral urea. ${ }^{28}$ They also suggested that the improvement seen in our initial report may be attributed to a nonspecific effect of antibiotics rather than to an effect of the eradication of $H$ pylori. However, in these studies, the patients had not been sufficiently treated for the gut flora before the eradication therapy for $H$ pylori. In the present study all patients were given kanamycin for two weeks before $H$ pylori eradication therapy to reduce the effect of the gut flora on hyperammonaemia. Blood ammonia concentration was reduced in all cases by the administration of kanamycin, lactulose, aminoleban ${ }^{\circledR}$, and a low protein diet. This effect seems to be strongly associated with the effect on the gut flora. Even after the treatment for the gut flora, the blood ammonia concentration in patients with diffuse distribution of $H$ pylori in the stomach (group I) was significantly reduced after $H$ pylori eradication compared with the concentration after the conventional treatment to reduce the gut flora. The ammonia concentration at 12 weeks after the eradication treatment was still significantly lower than that before therapy. The ammonia concentration in gastric juice was also significantly reduced after the eradication of $H$ pylori. In these patients, therefore, the decrease in blood ammonia after the eradication therapy is most likely dependent on the decrease in ammonia production by $H$ pylori in the stomach. However, no significant effect of the eradication therapy of $H$ pylori on hyperammonaemia was seen in $H$ pylori negative patients (group III) and the patients with regional distribution of $H$ pylori in the stomach (group II).

The phenol red dye spraying endoscopy is a good method for detecting the distribution of $H$ pylori in the stomach. Initially, we examined the relation of the distribution pattern of the endoscopy and the ammonia concentration in gastric juice in the healthy volunteers, and found that the gastric ammonia concentration in those with a diffuse distribution pattern was significantly higher than that in the subjects with the regional pattern. In this study the gastric ammonia concentration was also significantly higher in the patients with cirrhosis with a diffuse distribution than in those with a regional distribution. In addition, the urease activity of $H$ pylori isolates did not differ with group. Therefore, the number of the bacteria might be higher in the diffuse cases than in the regional cases.

These findings suggest that the contribution of ammonia produced by $H$ pylori to the systemic concentration depends on the number of bacteria and their distribution in the stomach. The long term control of recurrent hepatic encephalopathy is difficult. We suggest that eradication of $H$ pylori to reduce ammonia production in the stomach by the organism is effective in patients with hyperammonaemia with diffuse $H$ pylori infection in the stomach even after conventional therapy with a low protein diet, antibiotics, lactulose, and branched chain enriched amino acid solution.

This work was supported by a grant in aid for Developmental Scientific Research (B) 06557039 


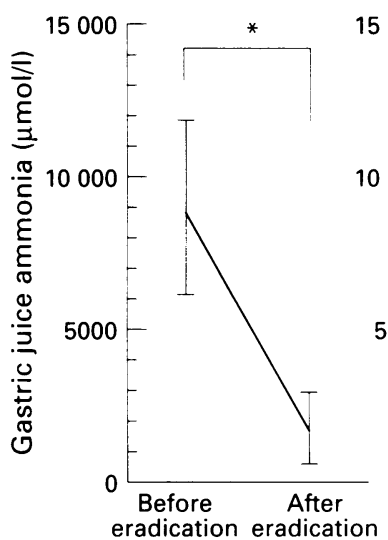

Group I

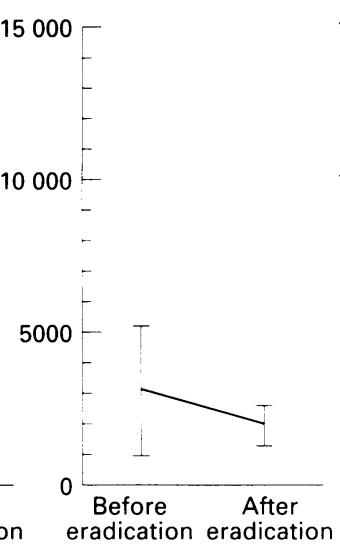

Group II

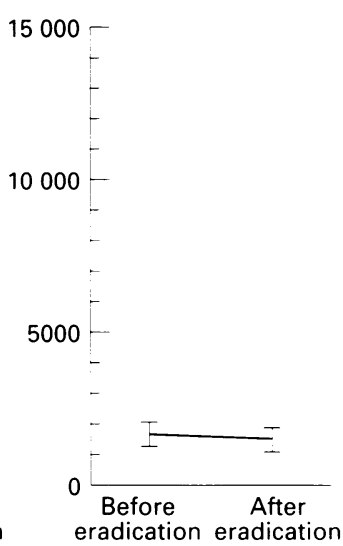

Group III

Figure 4: Changes in ammonia concentration in gastric juice before and after eradication therapy for $\mathrm{H}$ pylori. Each point and bar represents the mean (SD) of the cases (group I $n=6$; group II $n=6$; group III; $n=6$ ). ${ }^{*} p<0 \cdot 01$.

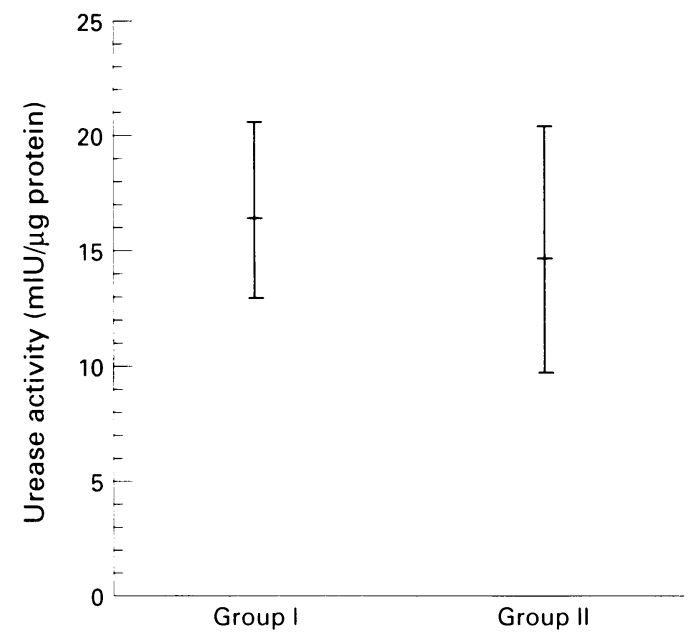

Figure 5: Urease activities of $\mathrm{H}$ pylori isolates from groups $I$ and II. Each point and bar represents the mean (SD) of the isolates (group I $n=6$; group II $n=6$ ).

1 Felipo V, Minana MD, Grisolia S. Paradoxical protection of both protein-free and high protein diets against acute ammonium intoxication. Biochem Biophys Res Commun 1988; 156: 506-10.

2 Bircher J, Muller J, Guggenheim P, Haemmerli LP Treatment of chronic portal-systemic encephalopathy with lactulose. Lancet 1966; i: 890-2.

3 Elkington SG, Floch $\mathrm{MH}$, Conn HO. Lactulose in the treatment of chronic portal-systemic encephalopathy. A double-blind clinical trial. N Engl f Med 1969; 281. 408-12.

4 Mortensen PB. The effect of oral-administered lactulose on colonic nitrogen metabolism and excretion. Hepatology 1992; 16: 1350-6.

5 Van Thiel DH, Fagiuoli S, Wright HI, Chien MC, Gavaler JS. Gastrointestinal transit in cirrhotic patients: effect of hepatic encephalopathy and its treatment. Hepatology 1994; 19: 67-71

6 Pirotte J, Guffens JM, Devos J. Comparative study of basal arterial ammonemia and of orally-induced hyperammonemia in chronic portal systemic encephalopathy,
treated with neomycin, lactulose and an association of neomycin and lactulose. Digestion 1974; 10: 435-44.

7 Wapnick S, Guinto R, Reizis I, LeVeen HH. Reduction of postoperative infection in elective colon surgery with preoperative administration of kanamycin and erythromycin. Surgery 1979; 85: 317-21.

8 Scevola D, Zambelli A, Concia E, Perversi L, Candiani C. Non-absorbable disaccharides plus neomycin in hepatic encephalopathy: do they enhance each other? Hepatology 1990; 12: 368-70.

9 Alexander T, Thomas K, Cherian AM, Kanakasabapathy Effect of three antibacterial drugs in lowering blood and stool ammonia production in hepatic encephalopathy. Indian F Med Res 1992; 96: 292-6.

10 Voorhies TM, Ehrlich ME, Duffy TE, Petito CK, Plum F. Acute hyperammonemia in the young primate: physiologic and neuropathologic correlates. Pediatr Res 1983; 17: 970-5.

11 Blei AT, Olafsson S, Therrien G, Butterworth RF. Ammonia-induced brain edema and intracranial hypertention in rats after portacaval anastomosis. hypertention in rats after por
Hepatologv 1994; 19: 1437-44.

12 Warren JR, Marshall BJ. Undentified curved bacilli on gastric epithelium in active chronic gastritis. Lancet 1983; i: $1273-5$.

13 Marshall BJ, Warren JR. Undentified curved bacilli in the stomach of patients with gastritis and peptic ulceration. Lancet 1984; i: 1311-5.

14 Johnston BJ, Reed PI, Ali MH. Campylobacter like organisms in duodenal and antral endoscopic biopsies: relationship to inflammation. Gut 1986; 27: 1132-7.

15 Blaser MJ. Helicobacter pylori and pathogenesis of gastroduodenal inflammation. I Infect Dis 1990; 161: gastroduc

16 Miyaji H, Kohli Y, Azuma T, Ito S, Hirai M, Ito Y, et al. Endoscopic cross-infection with Helicobacter pylori. Lancet 1995; 345: 464

17 Talley NJ, Zinsmeister AR, Weaver A, DiMagno EP, Carpenter HA, Perez Perez GI, Blaser MJ. Gastric adenocarcinoma and Helicobacter pylori infection. $7 \mathrm{Natl}$ Cancer Inst 1991; 83: 1734-9.

18 Parsonnet J, Friedman GD, Vandersteen DP, Chang Y, Vogelman JH, Orentreich N, Sibley RK. Helicobacter pylori infection and the risk of gastric carcinoma. $N$ Engl ҰMed 1991; 325: 1127-31.

19 Nomura A, Stemmermann GN, Chyou PH, Kato I, PerezPerez GI, Blaser MJ. Helicobacter pylori infection and gastric carcinoma among Japanese Americans in Hawaii. gastric carcinoma among Japanese
NEngl $₹$ Med 1991; 83: 1132-6.

20 Blaser MJ, Kobayashi K, Cover TL, Cao P, Feurer ID, Perez-Perez GI. Helicobacter pylori infection in Japanese patients with adenocarcinoma of the stomach. Int $\mathcal{F}$ Cancer 1993; 55: 799-802.

21 Parsonnet J, Hansen S, Rodriguez L, Gelb AB, Warnke RA, Jellum E, et al. Helicobacter pylori infection and gastric lymphoma. N Engl f Med 1994; 330: 1267-71.

22 Dunn BE, Campbell GP, Perez Perez GI, Blaser MJ. Purification and characterization of urease from Helicobacter pylori. 7 Biol Chem 1990; 265: 9464-9.

23 Perez Perez GI, Gower CB, Blaser MJ. Effect of cations on Helicobacter pylori urease activity, release, and stability. Helicobacter pylori urease activity,
Infect Immun 1994; 62: 299-302.

24 Ito S, Kohli Y, Kato T, Murakita H, Ohtaki Y, Hirai M, et al. Differences in urease activity in live Helicobacter pylori cultured from patients with gastroduodenal diseases. Eur 7 Gastroenterol Hepatol 1995; 7 (suppl 1): S83-8.

25 Ito S, Kohli Y, Kato T, Abe M, Ueda T. Significance of ammonia produced by Helicobacter pylori. Eur 7 Gastroenterol Hepatol 1994; 6: 167-74.

26 Ito S, Miyaji H, Azuma T, Li Y, Ito Y, Kato T, et al. Hyperammonaemia and Helicobacter pylori. Lancet 1995; 346: $124-5$.

27 Quero JC, Hartmann IJ, de Rooij F, Wilson JH, Schalm SW. Hyperammonaemia and Helicobacter pylori. Lancet 1995; 346: 713-4.

28 Plevris JN, Morgenstern R, Hayes PC, Bouchier IA. Hyperammonaemia in cirrhosis and Helicobacter pylor infection. Lancet 1995; 346: 1104

29 Fischer JE, Funovics JM, Aguirre A, James JH, Keane JM, Wesdorp RI, et al. The role of plasma amino acids in hepatic encephalopaty. Surgery 1975; 78: 276-90.

30 Weber FL Jr, Bagby BS, Licate L, Kelsen SG. Effects of branched-chain amino acids on nitrogen metabolism in patients with cirrhosis. Hepatology 1990; 11: 942-50.

31 Higuchi K, Shimizu Y, Nambu S, Miyabayashi C, Takahara $\mathrm{T}$, Saito $\mathrm{S}$, et al. Effects of an infusion of branched-chain amino acids on neurophysiological and psychometric testings in cirrhotic patients with mild hepatic testings in cirrhotic patients with mild hepatic

32 Kohli Y, Kato T, Iwaki M, Yamazaki Y, Hata M, Suzuki K, Ito $S$. The distribution of Helicobacter pylori in human gastric mucosa in vivo. Dig Endosc 1991; 3: 457-60.

33 Kohli Y, Kato T, Iwaki M, Ito S, Suzuki K. Endoscopic diagnosis of Helicobacter pylori distribution in gastric mucosa of patients with chronic gastritis. Eur $\mathcal{F}$ Gastroenterol Hepatol 1993; 5 (suppl 1): S127-31.

34 Hosking SW, Ling TK, Chung SC, Yung MY, Cheng AF, Sung JJ, $\mathrm{Li}$ AK. Duodenal ulcer healing by eradication of Helicobacter pylori without anti-acid treatment: randomised controlled trial. Lancet 1994; 343: 508-10

35 Sung JJ, Chung SC, Ling TK, Yung MY, Leung VK, Ng $\mathrm{EK}$, et al. Antibacterial treatment of gastric ulcers $\mathrm{EK}, e t$ al. Antibacterial treatment of gastric ulcers
associated with Helicobacter pylori. $N$ Engl $\mathrm{f} \mathrm{Med} \mathrm{1995;}$ 332: 139-42.

36 Labenz J, Borsch G. Role of Helicobacter pylori eradication in the prevention of peptic ulcer bleeding relapse.

37 Forbes GM, Glaser ME, Cullen DJ, Warren JR, Christiansen KJ, Marshall BJ, Collins BJ. Duodenal ulcer treated with Helicobacter pylori eradication: seven-year follow up. Lancet 1994; 343: 258-60. 